\title{
Short-Term Measurement Repeatability of a Simplified Intravoxel Incoherent Motion (IVIM) Analysis for Routine Clinical Diffusion- Weighted Imaging in Malignant Liver Lesions and Liver Parenchyma at $1.5 \mathrm{~T}$
}

\author{
Kurzzeitige Wiederholbarkeit einer vereinfachten Intravoxel-Inco- \\ herent-Motion (IVIM) -Analyse diffusionsgewichteter Bildgebung \\ aus der klinischen Routine für maligne Leberläsionen und Leber- \\ gewebe bei 1,5 T
}

Authors

Claus Christian Pieper, Alois Martin Sprinkart, Guido Mattias Kukuk, Petra Mürtz

Affiliation

Radiology, University-Hospital Bonn, Germany

Key words

MR-diffusion/perfusion, liver tumors, technical aspects

received 12.12 .2017

accepted 23.06.2018

Bibliography

DOI https://doi.org/10.1055/a-0649-1205

Published online: 6.8.2018

Fortschr Röntgenstr 2019; 191: 199-208

(c) Georg Thieme Verlag KG, Stuttgart · New York

ISSN 1438-9029

Correspondence

Priv.-Doz. Dr. Claus Christian Pieper

Radiologische Klinik, Universitätsklinik Bonn,

Sigmund-Freud-Str. 25, 53105 Bonn, Germany

Tel.: ++ 49/2 28/28715237

Fax: ++ 49/2 28/28719083

claus.christian.pieper@ukb.uni-bonn.de

\section{ZUSAMMENFASSUNG}

Zielsetzung Evaluierung der Messwiederholbarkeit von Parametern, die auf einer vereinfachten Intravoxel-IncoherentMotion (IVIM) -Analyse diffusionsgewichteter Bildgebung (DWI) mit 3b-Werten basieren.

Material und Methoden 24 Patienten (16 Männer, 8 Frauen, mittleres Alter 67 Jahre) mit malignen Lebertumoren (HCC: 10, Metastasen: 14) erhielten 29 Leber-MRTs bei 1,5 T. Eine Atem-getriggerte DWI $\left(b=0,50,800 \mathrm{~s} / \mathrm{mm}^{2}\right)$ wurde zweimal akquiriert. Parameterkarten des scheinbaren Diffusionskoeffizienten $\mathrm{ADC}(0,800)$, des geschätzten Diffusionskoeffizienten D' und der geschätzten Perfusionsfraktion $f^{\prime}$ wurden berechnet. Die Messwiederholbarkeit der Messwerte für eine Region-of-Interest (ROI) (jeweils einer pro Leberlappen in einer malignen Läsion und in Lebergewebe) wurde mit dem Variationskoeffizienten (CV) untersucht.

Ergebnisse 86 ROIs (43 Läsionen, 43 Parenchym) wurden analysiert. Die gemessenen Parameter unterschieden sich nicht signifikant zwischen den Messungen. Die Messwiederholbarkeit war exzellent für $\operatorname{ADC}(0,800)$ und $D^{\prime}$ und gut für $\mathrm{f}^{\prime}$ in Lebergewebe (CVs: 7,3 \%, 9,8 \%, 13,0 \%) und Läsionen (CVs: 7,5\%, 8,5\%, 11,0\%). Die CV-Werte unterschieden sich nicht signifikant zwischen Lebergewebe und Läsionen. Die Wiederholbarkeit war tendenziell besser im rechten Leberlappen, für Lebergewebe (CVs: $6,4 \%$ vs. $8,4 \%, 8,8 \%$ vs. $10,9 \%, 10,5 \%$ vs. $16,0 \%$ ) und für Läsionen (CVs: 6,9\% vs. 8,1 \%, 7,5\% vs. 9,5\%, $9,5 \%$ vs. $12,7 \%)$.

Schlussfolgerung Messungen mit dem vereinfachten IVIMModell zeigten eine exzellente Messwiederholbarkeit für die $A D C(0,800)$ und $D^{\prime}$-Werte und eine gute Messwiederholbarkeit für die f'-Werte sowohl für Läsionen als auch für Lebergewebe. Die Messwiederholbarkeit war im rechten Leberlappen besser als im linken Leberlappen.

\section{Kernaussagen:}

- Die vereinfachte IVIM-Analyse zeigt eine gute bis exzellente Messwiederholbarkeit der Parameter.

- Die Messwiederholbarkeit ist für den rechten Leberlappen besser als für den linken Leberlappen.

- Die vereinfachte IVIM-Analyse kann bei Diagnose und Monitoring maligner Lebertumoren helfen.

\section{ABSTRACT}

Objectives To evaluate measurement repeatability of parameters derived from simplified intravoxel incoherent motion (IVIM) analysis of diffusion-weighted imaging (DWI) using 3 b-values.

Materials and Methods 24 patients (16 male, 8 female, mean age: 67 years) with hepatic malignancy (HCC: 10 , metastases: 14) underwent 29 liver MRI examinations at 1.5 T. Respiratory-triggered DWI $\left(b=0,50,800 \mathrm{~s} / \mathrm{mm}^{2}\right)$ was 
acquired twice. Parameter maps of the apparent diffusion coefficient $\operatorname{ADC}(0,800)$, estimated diffusion coefficient $D^{\prime}$ and perfusion fraction $f^{\prime}$ were calculated. Measurement repeatability for a region of interest (ROI) placed in one lesion and liver parenchyma per lobe was assessed by intra-session variation coefficients (CV).

Results 86 ROls (43 lesions, 43 parenchymas) were analyzed. Parameters did not significantly differ between measurements. Repeatability was excellent for $\operatorname{ADC}(0,800)$ and $D^{\prime}$ and good for $f^{\prime}$ in parenchyma (CVs: $7.3 \%, 9.8 \%, 13.0 \%$ ) and lesions (CVs: $7.5 \%, 8.5 \%, 11.0 \%$ ). Differences in CV-values between liver and lesions were not significant. Repeatability was better for the right than for the left lobe by tendency, for parenchyma (CVs: $6.4 \%$ vs $8.4 \%, 8.8 \%$ vs $10.9 \%, 10.5 \%$ vs $16.0 \%$ ) and for lesions (CVs: $6.9 \%$ vs $8.1 \%, 7.5 \%$ vs $9.5 \%$, $9.5 \%$ vs $12.7 \%$ ).

Conclusion Measurement repeatability is excellent for ADC $(0,800)$ and $D^{\prime}$ values and good for $f^{\prime}$ values using the simplified IVIM approach, both in lesions and liver parenchyma.
Repeatability was better for lesions in the right compared to the left liver lobe.

\section{Key points:}

- Repeatability obtained by a simplified IVIM analysis approach is good to excellent.

- Repeatability is better for the right than for the left liver lobe.

- The simplified approach may be helpful in diagnosing and monitoring liver malignancies.

\section{Citation Format}

- Pieper CC, Sprinkart AM, Kukuk GM et al. Short-Term Measurement Repeatability of a Simplified Intravoxel Incoherent Motion (IVIM) Analysis for Routine Clinical DiffusionWeighted Imaging in Malignant Liver Lesions and Liver Parenchyma at 1.5T. Fortschr Röntgenstr 2019; 191: 199208

\section{Purpose}

Quantification of the apparent diffusion coefficient (ADC) from diffusion-weighted MR imaging (DWI) is widely used both for the evaluation of diffuse liver disease as well as for the characterization and assessment of treatment response of focal liver lesions [1 - 5]. The ADC can provide information on alterations of tissue cellularity, extracellular space tortuosity, and integrity of cell membranes (e.g. in developing necrosis) [1 - 5]. Conventionally, the $A D C$ is determined from diffusion-weighted images acquired with b-values between 0 and $500-1000 \mathrm{~s} / \mathrm{mm}^{2}$ assuming a mono-exponential relationship between signal intensity and the b-value [1, 3]. However, DWI is not only sensitive to molecular diffusion, but also to other intravoxel incoherent motion (IVIM) like perfusion due to pseudorandom organization of the capillary network at the voxel level [4-6]. Perfusion leads to additional signal attenuation at low b-values, whereas signal attenuation at higher b-values is mainly caused by molecular diffusion (true diffusion coefficient D) [7, 8]. A refined analysis can be performed based on the IVIM theory and the acquisition of at least four b-values. Influences of diffusion and perfusion can be separated assuming a bi-exponential behavior of signal intensity, yielding the diffusion coefficient $D$, the pseudo-diffusion coefficient $D^{*}$ and the perfusion fraction $f[6,8]$. In this model $D$ represents the mobility of water molecules in tissue and depends on the cellularity, tortuosity of the extracellular space, integrity of cell membranes, and viscosity of fluids $[4,6,8]$. f reflects the relative contribution of microvascular blood flow to the DWI signal, and D* depends on the blood velocity and length of microvessel segments $[6,8]$.

In current research, IVIM model-based analysis of DWI data is employed in diffuse [9-13] and focal liver disease [14 - 18]. However, in malignant liver lesions an IVIM analysis based on conventionally used bi-exponential fitting is difficult due to low $D^{*}$ - and f-values leading to fitting failures and poor reproducibility, especially for perfusion-related parameters [14, 16, 19-21]. Thus, for oncological liver applications, a simplified IVIM analysis based on only 3 b-values as introduced by Le Bihan [6] was recently used in several studies, yielding a stable voxel-wise estimation of $D$ and $f$ (called D' and f') [22-26]. Initial experience with this approach is promising, but data regarding measurement repeatability and reproducibility are lacking. In this context "repeatability" informs on measurement variations due to technically inconsistent readings by the same operator obtained on the identical subject with the same measurement and analysis equipment in a short time interval. It therefore provides information on the minimal achievable measurement error by controlling external sources of errors. "Reproducibility" on the other hand includes additional potential sources of variation such as a longer time interval between examinations (e. g. several days) [4].

The purpose of this study was to evaluate the repeatability of this simplified $3 \mathrm{~b}$-value IVIM analysis method, excluding possible influencing factors such as patient positioning within the MR scanner or confounding long-term variation in liver perfusion.

\section{Materials and Methods}

\section{Patients}

24 patients (16 male, 8 female, mean age: 67 years [range: $49-$ 86]) with hepatic malignancies underwent 29 standard liver MRI examinations with repeated acquisition of DWI in the clinical routine between October 2015 and March 2016. Data analysis was approved by the local institutional review board and patients gave written consent.

Patients suffered from the following primary or secondary malignancies: hepatocellular cancer $(n=10)$, neuroendocrine tumor $(n=5)$, renal cell cancer $(n=3)$, adenoid cancer $(n=2)$, colorectal 
cancer $(n=1)$, ovarian cancer $(n=1)$, uveal melanoma $(n=1)$, cholangiocellular carcinoma $(n=1)$. The majority of patients $(n=16)$ had undergone radioembolization, two patients had received chemoembolization, two were treated by chemotherapy, while four patients were treatment naive. In 12 cases tumor manifestation was unilobar, while the remaining 12 patients suffered from bilobar disease. 11 patients presented with liver cirrhosis. None of the patients suffered from hemochromatosis.

\section{MRI Technique}

All patients underwent MR imaging examinations of the liver on the same clinical 1.5T MRI scanner in supine position (Philips Healthcare, Best, The Netherlands; Ingenia; gradient system: maximum amplitude of $45 \mathrm{mT} / \mathrm{m}$, maximum slew rate of $200 \mathrm{~T} /$ $\mathrm{m} / \mathrm{s}$ ). A commercially available phased-array surface coil was used for signal reception. The standardized imaging protocol comprised a respiratory-triggered single-shot spin-echo echo-planar DWI sequence ( $\triangleright$ Table 1 ) with motion-probing gradients in three orthogonal directions and $3 \mathrm{~b}$-values $\left(0,50,800 \mathrm{~s} / \mathrm{mm}^{2}\right)$. The DWI sequence was acquired twice prior to contrast agent injection without moving the patient within the MR scanner. Isotropic diffusion-weighted images were reconstructed on the MRI system.

\section{Image Analysis and Definitions}

Image analyses were performed in consensus by a radiologist with 5 years of abdominal imaging experience, and a physicist with more than 17 years of experience in DWI. Both were blinded to patient-related information.

According to the IVIM concept of Le Bihan et al. [6], a two-

$\frac{S(b)}{S(0)}=f \cdot \exp ^{-D^{*} \cdot b}+(1-f) \cdot \exp ^{-D \cdot b}$

compartment model of extravascular and intravascular space was applied:

with $\mathrm{D}$ true diffusion coefficient, $\mathrm{D}^{*}$ pseudodiffusion coefficient, $f$ perfusion fraction, and $S(b)$ and $S(0)$ signal intensities with and without motion probing gradients, respectively. By using

$\frac{S(b)}{S(0)} \approx(1-f) \cdot \exp ^{-D \cdot b}$

the following simplified approach (high b-value approximation) as originally introduced by Le Bihan [6]:

$D$ and $f$ of the IVIM model were estimated as D' and f' as recent-

$D^{\prime}=A D C(50,800)=\frac{\ln (S(b 1))-\ln (S(b 2))}{b 2-b 1}$

$f^{\prime}=1-\frac{S(b 1)}{S(0)} \cdot e^{D^{\prime} \cdot b 1}$

ly applied to abdominal imaging for b-values b0 $=0$, b1 $=50$ and b2 $=800 \mathrm{~s} / \mathrm{mm}^{2}[22-25]$ :

$S(b)$ and $S(0)$ are the signal intensities with and without motion-probing gradients.
- Table 1 Diffusion-weighted imaging (DWI) sequence parameters.

- Tab. 1 Sequenzparameter der diffusionsgewichteten Sequenz (DWI).

\begin{tabular}{|l|l|}
\hline FOV (RLXAP)/orientation & $380 \times 326 \mathrm{~mm} /$ transverse \\
\hline $\begin{array}{l}\text { slice number/thickness/ } \\
\text { gap }\end{array}$ & $28 / 7.0 \mathrm{~mm} / 0.7 \mathrm{~mm}$ \\
\hline \begin{tabular}{l|l|} 
matrix/resolution \\
echo time (TE)
\end{tabular} & $112 \times 94 / 3.4 \times 3.5 \mathrm{~mm}$ \\
\hline $\begin{array}{l}\text { repetition time (TR) } \\
\text { imaging time per } \\
\text { respiration }\end{array}$ & 1 respiratory cycle \\
\hline
\end{tabular}

\begin{tabular}{|c|c|}
\hline $\begin{array}{l}\text { EPI-/half-Fourier-/ } \\
\text { SENSE-factor }\end{array}$ & $51 / 0.6 / 2$ \\
\hline diffusion gradients & 3 orthogonal directions \\
\hline b-values & $\begin{array}{l}0 \text { and } 50 \mathrm{~s} / \mathrm{mm}^{2}(\mathrm{NSA}=2), 800 \mathrm{~s} / \mathrm{mm}^{2} \\
(\mathrm{NSA}=6)\end{array}$ \\
\hline fat suppression method & SPIR \\
\hline water-fat shift/BW & $9.2 \mathrm{Pixel} / 23.6 \mathrm{~Hz}$ \\
\hline $\begin{array}{l}\text { BW in EPI frequency } \\
\text { direction }\end{array}$ & $1437.9 \mathrm{~Hz}$ \\
\hline acquisition time & around 3 min with respiratory gating \\
\hline \multicolumn{2}{|c|}{$\begin{array}{l}\text { SENSE: parallel imaging with sensitivity encoding, FOV: field of view, } \\
\text { RL: right-left, AP: anterior-posterior, EPI: echo-planar imaging, } \\
\text { NSA: number of averages, SPIR: spectral presaturation by inversion } \\
\text { recovery, BW: bandwidth. } \\
\text { SENSE: Parallele Bildgebung FOV: Sichtfeld, RL: rechts-links, AP: anterior- } \\
\text { posterior, EPI: Echo-planare Bildgebung, NSA: Anzahl der Mittelungen, } \\
\text { SPIR: Spektrale Fettsättigung, BW: Bandbreite }\end{array}$} \\
\hline
\end{tabular}

The apparent diffusion coefficient $\operatorname{ADC}(0,800)$ was also calculated:

$\operatorname{ADC}(0,800)=\frac{\ln (\mathrm{S}(\mathrm{b} 0))-\ln (\mathrm{s}(\mathrm{b} 2))}{\mathrm{b} 2-\mathrm{b} 0}$

Parameter maps were generated by voxel-wise calculation of ADC $(0,800), D^{\prime}$ and $f^{\prime}$ with dedicated software written in MATLAB (Math Works, Natick, MA).

Both DWI scans of the patient were displayed simultaneously. In each patient a target liver lesion with a diameter of $\geq 1 \mathrm{~cm}$ was selected per liver lobe (if present). For IVIM analysis of the first acquired DWI dataset a hand-drawn region of interest (ROI) was placed within a central slice of each lesion, avoiding (if possible) noticeable motion artifacts, pixel misalignments and susceptibility artifacts. Areas close to the rim of the lesion were excluded to avoid partial volume effects. A second ROI was placed in an adjacent area of tumor-free liver parenchyma. Large blood vessels were avoided. All ROls were drawn on $b=800 \mathrm{~s} / \mathrm{mm}^{2}$ images. ROI positions were visually cross-checked between all diffusionweighted images and then copied into the parameter maps. For the second DWI dataset, the same shape and size of the ROIs was used, but ROI positions were adapted to the actual lesion/liver position which may vary slightly between scans. For each ROI, 
the mean parameter value and standard deviation were determined and compared between the first and second measurement.

Measurement repeatability of the $\operatorname{ADC}(0,800)$, D' and f' for liver lesions and parenchyma was assessed by calculating the intra-session coefficient of variation (CV) and Lin's concordance correlation coefficient (CCC). Measurement repeatability was rated according to the intra-session CV as excellent ( $C V \leq 10 \%$ ), good (CV between 10 and 20\%), acceptable (CV between $20 \%$ and $30 \%)$ and poor ( $C V>30 \%)$ [14]. The grade of agreement between the two measurements was defined according to the CCC as almost perfect (CCC >0.90), substantial (CCC between 0.80 and 0.90 ), moderate (CCC between 0.65 and 0.80 ) and poor (CCC $<0.65$ ) [27]. Furthermore, we compared the CVs for lesions and liver parenchyma, right and left liver lobes (in patients with bilobar disease), locally treated and untreated lesions as well as cirrhotic and non-cirrhotic liver parenchyma.

\section{Statistical Analysis}

Statistics were performed using commercially available software (SPSS, version 22.0, IBM, Armonk, NY). Normal distribution of the data was assessed using Q-Q-plots. Bland-Altman analysis was performed to compare the mean relative differences of the parameters normalized to the mean values of the two measurements. Statistical significance $(p<0.05)$ for group differences was tested with Student's t-test for independent samples in case of intersubject comparisons, and with Student's t-test for paired samples in case of intrasubject comparisons.

\section{Results}

Overall 86 ROIs (43 in liver lesions, 43 in liver parenchyma) were analyzed. The results of statistical analyses are summarized in - Table 2.

Comparing $\operatorname{ADC}(0,800), D^{\prime}$ and $f^{\prime}$ values between test and retest measurements, no significant differences were found, neither for liver lesions nor for the parenchyma. Bland-Altman analysis revealed no systematic error between both measurements ( $\triangleright$ Table 2, $\triangleright$ Fig. 1). Example images and parameter maps are shown in > Fig. 2.

Overall, measurement repeatability of the $\operatorname{ADC}(0,800)$ and $D^{\prime}$ was excellent both for the liver parenchyma and lesions [ADC $(0,800)$ : CV $7.3 \%$ and $7.5 \%$, respectively; D': CV $9.8 \%$ and $8.5 \%$, respectively], while repeatability of f' was good (CV $13.0 \%$ and $11.0 \%)$.

While the repeatability of the $\operatorname{ADC}(0,800)$ was comparable between lesions and parenchyma $(p=0.899)$, the $C V s$ of $D^{\prime}$ and $f^{\prime}$ were slightly higher for the liver parenchyma compared to lesions, but without reaching statistical significance $(p=0.339$ and $p=0.353$, respectively). When only the right liver lobes were included, which are less susceptible to motion artifacts, there were also no significant differences between CVs of lesions and the parenchyma $\left(p=0.702\right.$ for the $\operatorname{ADC}(0,800), p=0.466$ for $D^{\prime}$ and $p=0.690$ for $\left.f^{\prime}\right)$.

Overall, the parenchyma and lesions in the right liver lobe showed better repeatability of all parameter values compared to the left liver lobe. In patients presenting with bilobar disease, a non-significant trend was found for ADC, D' and f' towards higher CVs for the left liver lobe compared to the right lobe, both for the liver parenchyma $(p=0.097, p=0.191$ and $p=0.158$, respectively) and lesions $(p=0.469, p=0.282$ and $p=0.748$, respectively). The best repeatability was observed for the $\operatorname{ADC}(0,800)$ of the parenchyma and lesions in the right liver lobe (6.4\% and $6.9 \%)$; worst values for $f^{\prime}$ in the left liver lobe (16.0\% and $12.7 \%$ ).

There was substantial to almost perfect correlation between the two measurements for the $\operatorname{ADC}(0,800)$, $D^{\prime}$ and $f^{\prime}$ of liver lesions with slightly lower correlation coefficients for lesions in the left liver lobe ( $\triangleright$ Table 2). For the liver parenchyma there was only poor to moderate correlation between the measurements for the $\operatorname{ADC}(0,800)$ and $D^{\prime}$ with poor values especially occurring in the left liver lobe. In contrast, there was a substantial inter-measurement correlation for f'-values with almost perfect correlation in the right liver lobe.

Additional comparison of measurement repeatability between clinically defined groups yielded the following results: Compared to locally treated lesions ( $n=29)$, untreated lesions $(n=6)$ showed significantly higher CVs for the ADC and D' ( $p=0.006$ and $p=0.014$, respectively), whereas the CVs of $f^{\prime}$-values did not differ significantly $(p=0.385)$. When comparing cirrhotic and noncirrhotic liver parenchyma, the CVs did not differ significantly for $\operatorname{ADC}(0,800)$, D' and $f^{\prime}(p=0.389, p=0.528$ and $p=0.247$, respectively).

\section{Discussion}

Intravoxel incoherent motion (IVIM) model-based analysis can yield information on the amount of microvasculature (perfusion fraction f), blood-flow velocity and vessel architecture (pseudodiffusion coefficient $D^{*}$ ), and is increasingly being investigated for application in body imaging [6, 8]. However, before wider clinical application of this technique can be recommended, technical parameters especially the repeatability and reproducibility of measurements need to be determined. Although quantitative IVIM-based analysis of DWI data in the liver is increasingly being employed both for diffuse [9-13] and focal liver disease [1418 ], most data on measurement reproducibility to date have been obtained for normal liver tissue [16, 28-30].

For bi-exponential IVIM analysis mostly unconstrained non-linear least squares (NLLS) fitting procedures with simultaneous determination of $D, D^{*}$ and $f$ (so-called full fitting) are used. However, these are problematic in malignant liver lesions. Weak bi-exponential signal decay (low $D^{*}$ ) and weak IVIM effect (low f) as observed in malignant lesions lead to fitting failures and poor reproducibility $[14,16,19-21]$. Improved stability can be achieved for IVIM approaches using a high b-value approximation of a mono-exponential signal for $\mathrm{D}$ determination like segmented fitting [31 - 33] and simplified IVIM [34], which both decrease the degree of freedom by determining the parameters step-by-step. In segmented fitting, parameters are determined by fitting procedures, whereas in simplified IVIM explicit approximation formulas in combination with three or four acquired b-values are used. D and $f$ can be approximated from only three $b$-values and $D, f$ and 
- Table 2 Measurement results and test-retest repeatability of ADC, D' and f' for malignant liver lesions and liver parenchyma.

- Tab.2 Messergebnisse und Test-Retest-Repeatability von ADC, D' und f' von malignen Leberläsionen und Lebergewebe.

\begin{tabular}{|c|c|c|c|c|c|c|}
\hline & \multicolumn{3}{|l|}{ malignant lesions } & \multicolumn{3}{|l|}{ liver parenchyma } \\
\hline & overall $(n=43)$ & right $(n=23)$ & left $(n=20)$ & overall $(n=43)$ & right $(n=23)$ & left $(n=20)$ \\
\hline \multicolumn{7}{|l|}{$\operatorname{ADC}(0,800)$} \\
\hline test & $1417 \pm 412(529-2864)$ & $1514 \pm 428(981-2864)$ & $1298 \pm 369(529-2060)$ & $1359 \pm 205(968-1925)$ & $1394 \pm 233(1036-1925)$ & $1319 \pm 165(968-1657)$ \\
\hline retest & $1418 \pm 399(637-2698)$ & $1480 \pm 442(935-2698)$ & $1347 \pm 341(637-2002)$ & $1363 \pm 216(1020-1888)$ & $1387 \pm 235(1055-1888)$ & $1336 \pm 195(1020-1729)$ \\
\hline mean & $1416 \pm 395(588-2781)$ & $1497 \pm 426(980-2781)$ & $1322 \pm 342(588-1904)$ & $1361 \pm 194(1032-1895)$ & $1390 \pm 224(1123-1895)$ & $1328 \pm 150(1032-1601)$ \\
\hline wSD & $103 \pm 81(2-271)$ & $108 \pm 80(2-271)$ & $103 \pm 87(5-249)$ & $98 \pm 64(7-247)$ & $84 \pm 44(7-165)$ & $114 \pm 80(17-247)$ \\
\hline CV [\%] & $7.5 \pm 5.8(0.2-19.1)$ & $6.9 \pm 5.1(0.2-16.4)$ & $8.1 \pm 6.7(0.3-19.1)$ & $7.3 \pm 4.8(0.4-18.8)$ & $6.4 \pm 3.8(0.4 \pm 13.6)$ & $8.4 \pm 5.7(1.4-18.8)$ \\
\hline $\begin{array}{l}\text { mean percentage } \Delta \\
(95 \% \text { LoA) [\%] }\end{array}$ & $0.14(-24.77-25.91)$ & $-2.21(-26.34-20.76)$ & $3.73(-23.72-32.60)$ & $0.29(-24.28-24.76)$ & $-0.48(-21.52-20.46)$ & $1.35(-27.41-29.67)$ \\
\hline CCC & 0.894 & 0.910 & 0.853 & 0.688 & 0.832 & 0.388 \\
\hline \multicolumn{7}{|c|}{ true diffusion coefficient $\mathrm{D}^{\prime}$} \\
\hline test & $1297 \pm 396(503-2807)$ & $1416 \pm 433(898-2807)$ & $1160 \pm 302(503-1744)$ & $1095 \pm 177(798-1491)$ & $1118 \pm 176(799-1491)$ & $1069 \pm 180(812-1486)$ \\
\hline retest & $1311 \pm 390(589-2643)$ & $1396 \pm 444(832-2643)$ & $1212 \pm 298(589-2036)$ & $1105 \pm 200(676-1602)$ & $1118 \pm 206(731-1602)$ & $1091 \pm 196(676-1460)$ \\
\hline mean & $1303 \pm 381(565-2725)$ & $1406 \pm 430(898-2725)$ & $1186 \pm 283(565-1890)$ & $1100 \pm 164(799-1536)$ & $1118 \pm 174(864-1536)$ & $1080 \pm 153(799-1363)$ \\
\hline wSD & $106 \pm 79(0.1-256)$ & $108 \pm 74(0.1-244)$ & $110 \pm 90(0.4-256)$ & $106 \pm 79(0.7-348)$ & $93 \pm 72(0.7-206)$ & $121 \pm 95(2-348)$ \\
\hline CV [\%] & $8.5 \pm 6.4(0.01-23.0)$ & $7.5 \pm 5.5(0.01-19.6)$ & $9.5 \pm 7.4(0.03-23.0)$ & $9.8 \pm 7.3(0.1-28.1)$ & $8.8 \pm 6.5(0.1-21.7)$ & $10.9 \pm 8.2(0.2-28.1)$ \\
\hline $\begin{array}{l}\text { mean percentage } \Delta \\
(95 \% \text { LoA) [\%] }\end{array}$ & $0.93(-28.43-30.77)$ & $-1.39(-27.87-23.91)$ & $4.35(-27.80-32.36)$ & $0.91(-33.50-34.70)$ & $-0.01(-31.25-30.33)$ & $2.10(-36.43-40.05)$ \\
\hline $\mathrm{CCC}$ & 0.886 & 0.919 & 0.772 & 0.501 & 0.646 & 0.319 \\
\hline \multicolumn{7}{|l|}{ perfusion fraction $\mathrm{f}^{\prime}$} \\
\hline test & $96.0 \pm 75.7(3.5-310)$ & $85.7 \pm 70.8(3.5-310)$ & $108 \pm 81.1(16.4-306.8)$ & $181.5 \pm 74.5(68.8-374.4)$ & $187 \pm 81(68.8-374.4)$ & $175.4 \pm 67.9(93.0-342.8)$ \\
\hline retest & $99.2 \pm 72.7(1.7-273.3)$ & $83.5 \pm 58.8(1.7-233)$ & $117.2 \pm 84.0(15.1-273.3)$ & $177.2 \pm 78.8(76.7-459.6)$ & $180.3 \pm 83.8(76.7-459.6)$ & $173.6 \pm 74.7(80.6-377.9)$ \\
\hline mean & $97.6 \pm 73.1(2.6-290.1)$ & $84.6 \pm 64.3(2.6-267.1)$ & $112.5 \pm 81.2(15.8-290.1)$ & $179.4 \pm 74.2(72.8-412.0)$ & $183.6 \pm 80.5(72.8-412.0)$ & $174.5 \pm 68.1(92.2-360.4)$ \\
\hline wSD & $10.5 \pm 14.8(0.1-60.9)$ & $7.7 \pm 12.0(0.1-60.9)$ & $13.9 \pm 17.0(0.1-59.5)$ & $22.3 \pm 15.7(1.1-67.4)$ & $20.0 \pm 14.9(1.9-67.4)$ & $25.0 \pm 16.5(1.1-64.8)$ \\
\hline CV [\%] & $11.0 \pm 11.4(0.1-49.0)$ & $9.5 \pm 10.2(0.1-49.0)$ & $12.7 \pm 12.6(0.2-47.8)$ & $13.0 \pm 9.2(1.0-36.0)$ & $10.5 \pm 5.3(1.0-20.1)$ & $16.0 \pm 11.7(1.2-36.0)$ \\
\hline $\begin{array}{l}\text { mean percentage } \Delta \\
(95 \% \text { LoA) [\%] }\end{array}$ & $2.51(-40.34-46.80)$ & $-2.54(-39.31-38.72)$ & $8.26(-40.77-55.34)$ & $-2.40(-47.10-41.03)$ & $-3.52(-35.61-29.23)$ & $-1.07(-58.45-52.57)$ \\
\hline CCC & 0.939 & 0.950 & 0.928 & 0.872 & 0.906 & 0.818 \\
\hline
\end{tabular}



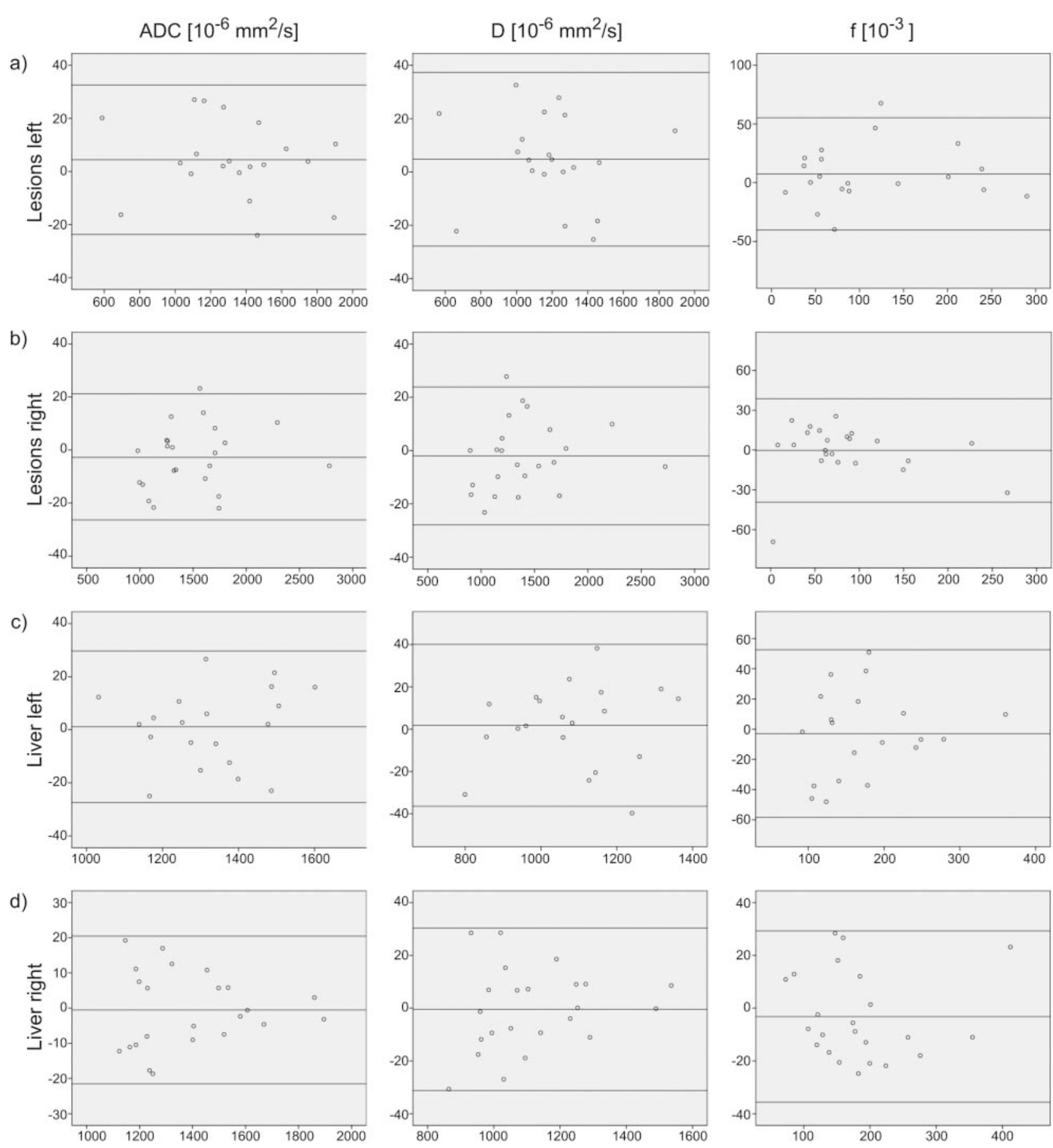

- Fig. 1 Bland-Altman plots for the conventional $\operatorname{ADC}(0,800)$, the diffusion sensitive parameter $\mathrm{D}^{\prime}$ and the perfusion sensitive parameter $\mathrm{f}^{\prime}$ of lesions in the left $\mathbf{a}$ and right $\mathbf{b}$ liver lobe, as well as for liver parenchyma in the left $\mathbf{c}$ and right $\mathbf{d}$ liver lobe.

- Abb. 1 Bland-Altman-Diagramme für den konventionellen $\mathrm{ADC}(0,800)$, den diffusionssensitiven Parameter $\mathrm{D}^{\prime}$ und den perfusionssensitiven Parameter f' von Läsionen des linken $\mathbf{a}$ und rechten $\mathbf{b}$ Leberlappens sowie für Leberparenchym des linken $\mathbf{c}$ und rechten $\mathbf{d}$ Leberlappens.

D* from only four b-values. For lesion characterization, it turned out that simplified IVIM with four b-values had no further benefit to simplified IVIM with three b-values [34]. By using simplified IVIM based on three b-values, a stable voxel-wise estimation of the diffusion coefficient ( $\left.D^{\prime}\right)$ and the perfusion fraction ( $\left.f^{\prime}\right)$ within acceptable acquisition times can be performed [22 - 26].

The aim of the present study was to determine the measurement repeatability of the three b-value approach, i. e. consistency of measurement results while minimizing errors due to long-term 


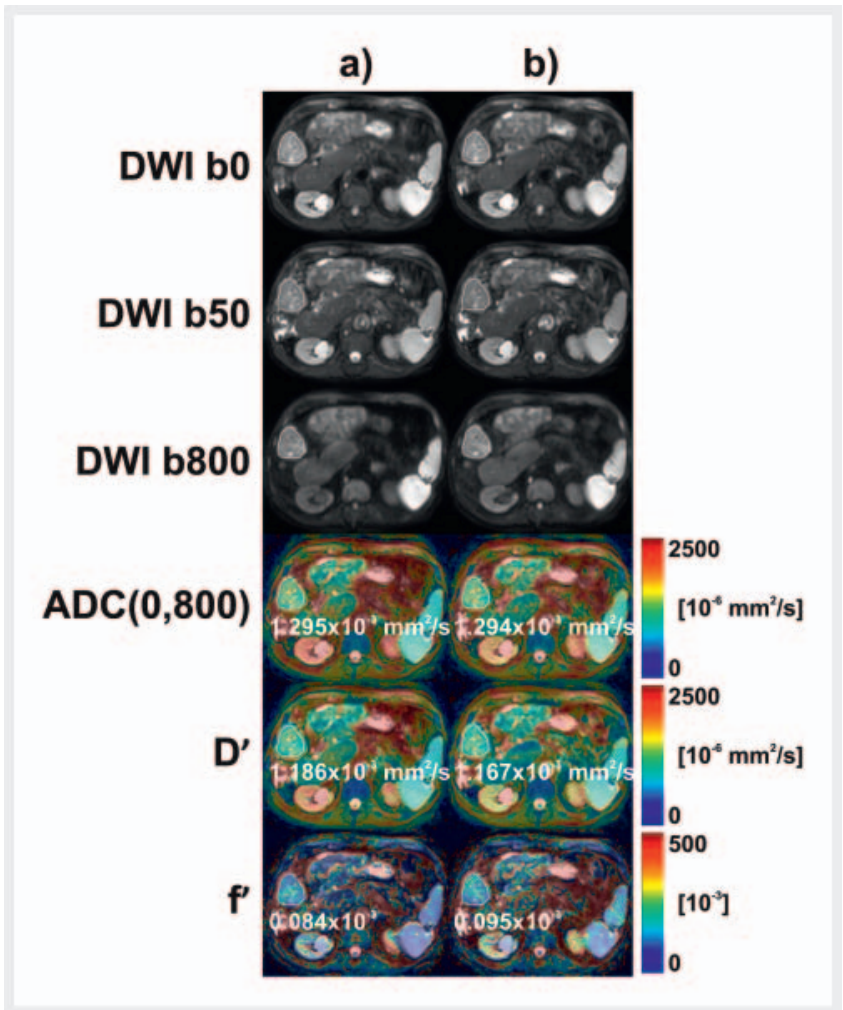

- Fig. 2 Typical example of intravoxel incoherent motion (IVIM)based parameter maps for a multifocal hepatocellular carcinoma (HCC). Original diffusion-weighted images with $b=0,50$, $800 \mathrm{~s} / \mathrm{mm}^{2}$ are presented together with conventional $\operatorname{ADC}(0,800)$, diffusion sensitive $D^{\prime}$ and perfusion sensitive $\mathrm{f}^{\prime}$ parameter maps for a initial and $\mathbf{b}$ repeated acquisition. The parameter maps are displayed as color-coded overlays over DWI $b=0$. Analyzed regions of interest are marked in white. For $A D C(0,800)$, D' and f', a coefficient of variation (CV) of $0.08 \%, 1.61 \%$ and $12.29 \%$, respectively, was reached.

- Abb. 2 Typisches Beispiel für Intravoxel-Incoherent-Motion (IVIM) basierte Parameterkarten eines Patienten mit multifokalem hepatozellulärem Karzinom (HCC). Original diffusionsgewichtete Bilder mit $b=0,50,800 \mathrm{~s} / \mathrm{mm}^{2}$ sind zusammen mit dem konventionellen $\operatorname{ADC}(0,800)$, den diffusionssensitiven $D^{\prime}$ - und den perfusionssensitiven f'-Parameterkarten für die $\mathbf{a}$ erste und $\mathbf{b}$ zweite Akquisition abgebildet. Die Parameterkarten sind als farbkodiertes Overlay über dem DWI-Bild mit $\mathrm{b}=0$ dargestellt. Die analysierten Regions-of-Interest sind in weiß eingezeichnet. Für $\operatorname{ADC}(0,800)$, D' und f' ergaben sich Variationskoeffizienten von $0,08 \%, 1,61 \%$ und $12,29 \%$.

biological variability [4]. We chose to determine repeatability instead of reproducibility because reproducibility can additionally be influenced by long-term biological changes for example in portal venous flow [35]. A recent study showed no significant differences between the repeatability and reproducibility of IVIM parameters determined by NLLS fitting for the liver parenchyma [28]. This means that variations of the NLLS fitting results were greater than changes due to repositioning of the patients or physiological long-term changes. This might be different for simplified IVIM.
With regard to repeatability and reproducibility, a comparison of different IVIM-based studies is difficult as measurement results depend on the choice of b-values, field strength, acquisition technique, methodology of parameter analysis, and the investigated target. The reported reproducibility of overall ADC and D was generally better than that of $f$ and $D^{*}$ irrespective of the analysis method but showed a wide range of variation: for the ADC and $\mathrm{D}$, the coefficients of variation (CV) ranged from $2.3-15.6 \%$ and $3.2-25.3 \%$, respectively, while the maximum percentage variation of $f$ and $D^{*}$ has been described as high as $7.7-241 \%$ and $14.6-2120 \%$, respectively [9, 14, 16, 28-30, 36-38] ( $\triangleright$ Table 3 ). Influencing factors of repeatability and reproducibility leading to this wide range of variation between different studies are discussed in the following paragraphs:

First, measurement reproducibility especially of perfusionassociated parameters depends on the method of data analysis. This is especially true for malignant lesions. Full NLLS fitting yielded the worst reproducibility of IVIM parameters especially in malignant lesions [16, 28-30]. In a study employing voxel-wise NLLS (with respiratory triggering), the reproducibility of $f$ and $D *$ was considerably worse for metastases compared to the surrounding liver parenchyma [16]. By comparison, Bayesian fitting yielded better reproducibility than NLLS fitting with only slightly worse results in malignant lesions compared to normal liver [14, 36, 37]. Segmented fitting produced the lowest variation coefficients of IVIM parameters but has not yet been evaluated for malignant lesions [9-13, 38]. For our presented simplified IVIM approach with voxel-wise analysis (respiratory triggering), the CVs (repeatability) of $D^{\prime}$ and $f^{\prime}$ in the case of normal liver $(9.8 \%$ and $13.0 \%$, respectively) were comparable to the CVs (reproducibility) of other analysis methods. However, the coefficients of variation of D' and f' of malignant lesions were better than those obtained with other methods to date. However, the reproducibility needs to be determined for the simplified approach, especially in focal lesion changes due to repositioning. Overall, similar or even better repeatability was reached in malignant lesions compared to surrounding tissue ( 8.5 vs. $9.8 \%$ for D' and $11.0 \%$ vs. $13.0 \%$ for $\left.f^{\prime}\right)$. This may be due to differences between the methods of parameter calculation/fitting. In contrast to fitting-based approaches, the simplified method is not limited by low $\mathrm{D}^{*}$ and $\mathrm{f}$ values. Results depend primarily on the signal-to-noise ratio, which is typically higher in malignant lesions due to stronger diffusion restriction, lower perfusion effects and longer T2-relaxation times [39].

Second, measurement reproducibility is influenced by the method of data acquisition. Free-breathing DWI acquisition is associated with pixel misalignments which may lead to measurement errors especially when examining circumscribed lesions, like malignant tumors. The use of respiratory triggering as performed in our work can improve reproducibility. As this has only been done before for liver tissue and not for malignant lesions [29, 37, 38], we cannot put our data into perspective.

Third, repeatability is influenced by physiological processes. As observed previously, the repeatability of IVIM parameters in our study for left hepatic lobes was worse compared to that for right lobes, probably due to cardiac motion. Repeatability may further be improved by echocardiography triggering [29]. However, com- 
- Table 3 Summary of study results.

- Tab.3 Zusammenfassung der Ergebnisse publizierter Studien.

\begin{tabular}{|c|c|c|c|c|c|c|c|c|c|c|}
\hline reference & $\begin{array}{l}\text { field } \\
\text { strength }\end{array}$ & b-values in $\mathrm{s} / \mathrm{mm}^{2}$ & $\begin{array}{l}\text { motion con- } \\
\text { trol }\end{array}$ & analysis & investigated tissue & parameter & $A D C$ & D & $f$ & $\mathbf{D}^{*}$ \\
\hline $\begin{array}{l}\text { Gurney-Cham- } \\
\text { pion et al. } 2016 \\
{[28]}\end{array}$ & $3.0 \mathrm{~T}$ & $\begin{array}{l}0,10,20,30,40,50 \\
65,80,100,125,175 \\
250,375,500\end{array}$ & RT & $\begin{array}{l}\text { NLLS biexp fit, } \\
\text { ROI-wise }\end{array}$ & $\begin{array}{l}\text { liver healthy } \\
\text { large ROI }(n=16) \\
\text { small ROI }(n=16)\end{array}$ & $\mathrm{CV}$ & $\begin{array}{l}\text { NA } \\
\text { NA }\end{array}$ & $\begin{array}{l}12 \% \\
13 \%\end{array}$ & $\begin{array}{l}47 \% \\
34 \%\end{array}$ & $\begin{array}{l}150 \% \\
77 \%\end{array}$ \\
\hline $\begin{array}{l}\text { Lee et al. } 2015 \\
\text { [29] }\end{array}$ & $1.5 \mathrm{~T}$ & $\begin{array}{l}0,30,60,100,150 \\
200,400,600,900\end{array}$ & $\mathrm{RT} / \mathrm{FB} / \mathrm{ET}$ & $\begin{array}{l}\text { NLLS biexp fit, } \\
\text { voxel-wise, right } \\
\text { and left lobe }\end{array}$ & $\begin{array}{l}\text { liver healthy } \\
\text { RT, right lobe }(n=12) \\
\text { FB, right lobe }(n=12)\end{array}$ & $\mathrm{CV}$ & $\begin{array}{l}2.3 \% \\
4.3 \%\end{array}$ & $\begin{array}{l}3.2 \% \\
4.1 \%\end{array}$ & $\begin{array}{l}11.9 \% \\
15.8 \%\end{array}$ & $\begin{array}{l}75.0 \% \\
74.2 \%\end{array}$ \\
\hline $\begin{array}{l}\text { Andreou et al. } \\
2013 \text { [16] }\end{array}$ & $1.5 \mathrm{~T}$ & $\begin{array}{l}0,25,50,75,100 \\
250,500,900\end{array}$ & RT & $\begin{array}{l}\text { NLLS biexp fit, } \\
\text { voxel-wise }\end{array}$ & $\begin{array}{l}\text { liversurr. }(n=14) \\
\text { Met. }(n=14)\end{array}$ & $\max . \Delta[\%]$ & $\begin{array}{l}6.8 \% \\
14.7 \%\end{array}$ & $\begin{array}{l}8.1 \% \\
25.3 \%\end{array}$ & $\begin{array}{l}25.1 \% \\
241 \%\end{array}$ & $\begin{array}{l}59 \% \\
2120 \%\end{array}$ \\
\hline $\begin{array}{l}\text { Dyvorne et al. } \\
2014[30]\end{array}$ & $1.5 \mathrm{~T}$ & $\begin{array}{l}0,15,30,45,60,75 \\
90,105,120,135 \\
150,175,200,400 \\
600,800\end{array}$ & RT & $\begin{array}{l}\text { NLLS biexpfit, } \\
\text { ROI-wise, right lobe, } \\
\text { bipolar DW-gradi- } \\
\text { ents }\end{array}$ & $\begin{array}{l}\text { liver healthy and diffuse } \\
\text { disease }(n=14)\end{array}$ & $\mathrm{CV}$ & NA & $12.0 \%$ & $32.3 \%$ & $193.8 \%$ \\
\hline $\begin{array}{l}\text { Dyvorne et al. } \\
2013 \text { [37] }\end{array}$ & $1.5 \mathrm{~T}$ & $\begin{array}{l}0,15,30,45,60,75 \\
90,105,120,135 \\
150,175,200,400 \\
600,800\end{array}$ & $\begin{array}{l}\text { RT } \\
\text { FB }\end{array}$ & $\begin{array}{l}\text { Bayesian fit, } \\
\text { ROI-wise, right lobe, } \\
\text { bipolar DW-gradi- } \\
\text { ents }\end{array}$ & $\begin{array}{l}\text { liver healthy }(n=20) \\
\text { diffuse disease }(n=20)\end{array}$ & $\mathrm{CV}$ & $\begin{array}{l}\text { NA } \\
\text { NA }\end{array}$ & $\begin{array}{l}9.3 \% \\
6.8 \%\end{array}$ & $\begin{array}{l}17.9 \% \\
35.6 \%\end{array}$ & $\begin{array}{l}37.3 \% \\
55.5 \%\end{array}$ \\
\hline $\begin{array}{l}\text { Jajamovich et al. } \\
2014 \text { [36] }\end{array}$ & $3.0 \mathrm{~T}$ & $\begin{array}{l}0,15,30,45,60,75 \\
90,105,120,135 \\
150,175,200,400 \\
600,800\end{array}$ & $\mathrm{FB}$ & $\begin{array}{l}\text { Bayesian fit, ROI- } \\
\text { wise, right lobe }\end{array}$ & $\begin{array}{l}\text { liver healthy and diffuse } \\
\text { disease }(n=30)\end{array}$ & $\mathrm{CV}$ & $8.2 \%$ & $15.2 \%$ & $20.4 \%$ & $51.6 \%$ \\
\hline $\begin{array}{l}\text { Kakite et al. } \\
2015 \text { [14] }\end{array}$ & $3.0 \mathrm{~T}$ & $\begin{array}{l}0,15,30,45,60,75 \\
90,105,120,135 \\
150,175,200,400 \\
600,800\end{array}$ & $\mathrm{FB}$ & $\begin{array}{l}\text { Bayesian fit, ROI- } \\
\text { wise, right lobe in } \\
\text { case of liver }\end{array}$ & $\begin{array}{l}\text { liversurr. }(n=11) \\
\text { HCC }(n=15) \\
\text { HCC right }(n=10) \\
\text { HCC left }(n=5)\end{array}$ & $\mathrm{CV}$ & $\begin{array}{l}8.8 \% \\
15.6 \% \\
11.6 \% \\
18.4 \%\end{array}$ & $\begin{array}{l}13.2 \% \\
19.7 \% \\
19.0 \% \\
6.8 \%\end{array}$ & $\begin{array}{l}25.3 \% \\
37.3 \% \\
32.9 \% \\
57.0 \% \\
\end{array}$ & $\begin{array}{l}59.0 \% \\
60.6 \% \\
61.4 \% \\
53.1 \% \\
\end{array}$ \\
\hline $\begin{array}{l}\text { Cohen et al. } \\
2015 \text { [9] }\end{array}$ & $1.5 \mathrm{~T}$ & $\begin{array}{l}0,10,25,50,100 \\
150,200,400,800\end{array}$ & RT & segmented fitting & $\begin{array}{l}\text { liver healthy } \\
\text { voxel-wise } \\
\text { ROI-wise }\end{array}$ & $\mathrm{CV}$ & & & & $\begin{array}{l}10 \% \\
28 \% \\
\end{array}$ \\
\hline $\begin{array}{l}\text { Patel et al. } 2010 \\
\text { [38] }\end{array}$ & $1.5 \mathrm{~T}$ & $\begin{array}{l}0,50,100,150,200 \\
300,500,700,1000\end{array}$ & $\mathrm{FB} / \mathrm{RT}$ & $\begin{array}{l}\text { segmented fitting, } \\
\text { ROI-wise, only right } \\
\text { lobe }\end{array}$ & $\begin{array}{l}\text { liver healty } \\
\text { RT }(n=5) \\
\text { FB }(n=4)\end{array}$ & $\mathrm{CV}$ & $\begin{array}{l}3.0 \% \\
3.4 \%\end{array}$ & $\begin{array}{l}3.8 \% \\
6.4 \%\end{array}$ & $\begin{array}{l}7.7 \% \\
16.0 \%\end{array}$ & $\begin{array}{l}14.6 \% \\
39.1 \%\end{array}$ \\
\hline $\begin{array}{l}\text { Current study } \\
\text { (Pieper et al.) }\end{array}$ & $1.5 \mathrm{~T}$ & $0,50,800$ & RT & $\begin{array}{l}\text { simplified ap- } \\
\text { proach, voxel-wise }\end{array}$ & $\begin{array}{l}\text { liver surr. }(n=24) \\
\text { malignant }(n=24)\end{array}$ & $\mathrm{CV}$ & $\begin{array}{l}7.3 \% \\
7.5 \%\end{array}$ & $\begin{array}{l}9.8 \% \\
8.5 \%\end{array}$ & $\begin{array}{l}13.0 \% \\
11.0 \%\end{array}$ & $\begin{array}{l}\text { NA } \\
\text { NA }\end{array}$ \\
\hline
\end{tabular}


bined cardiac and respiratory triggering leads to a considerable penalty in acquisition time and is therefore not routinely employed.

Fourth, prior treatment may also influence repeatability. Even though no statistically significant differences have been described for treated and untreated HCCs for ROI-wise Bayesian fitting [14], our study found better repeatability of ADC and D' for liver lesions after treatment by radioembolization or chemoembolization. These therapies usually induce a certain degree of tissue necrosis within the lesion which is associated with increasing ADC values $[1-3,5]$. This in turn is associated with an increased signal-tonoise ratio and constant absolute measurement errors, so posttherapeutic relative measurement accuracy will be higher.

For clinical application it is important to detect differences in IVIM parameters between different groups of patients or changes after treatment which have to be larger than the measurement error. Thus, adequate measurement reproducibility of the quantified parameters is essential. In this study, we demonstrated good repeatability values of the simplified IVIM approach, which explains the successful use in first clinical oncological liver applications. The simplified IVIM approach was able to improve lesion characterization [25], allowed for identification of patients likely to develop early blood-flow stasis during resin-based radioembolization [23], and improved response assessment after radioembolization [24]. Patients developing early stasis were characterized by a significantly lower estimated perfusion fraction $\mathrm{f}^{\prime}$ by a mean of about $60 \%$ [23]. Likewise patients showing tumor growth or shrinkage after treatment showed relative group differences of f' and D' of about $50 \%$ [24]. In both studies group differences are considerably above the measurement variation observed in the present study.

The results of our study are limited by several factors. First, we included different tumor types and treated and untreated lesions in order to investigate the overall effect over a wide spectrum of existing parameter values. A separate analysis of different tumor entities would also be interesting but needs larger patient numbers. Second, measurement repeatability instead of reproducibility was examined to avoid biological alterations. However, the influence of repositioning should also be investigated in the future for simplified IVIM. When using NLLS fitting, no statistically significant differences were found between repeatability and reproducibility for liver tissue which means that the error due to repositioning is smaller than the error of the fitting procedure [28]. This might be different for simplified IVIM and in case of lesions. This is particularly important when employing IVIM analysis for follow-up after therapy in which typically the second examination is performed several weeks later. Third, as described above, we investigated simplified IVIM with three b-values. Thus, the determination of $D^{*}$ was not possible. However, it provides numerically stable voxel-wise calculation of parameter maps of $D^{\prime}$ and $f^{\prime}$ at low acquisition times. These maps can be clinically used for visual inspection and D' and f' may serve as standardized empirical biomarkers indicating nonspecific pathological changes or therapy responses. Test and retest measurements with four b-value simplified IVIM may be interesting to investigate in further studies. As in other IVIM-based procedures, analysis remains challenging due to imaging artifacts in DWI. Thus, experienced operators are needed to recognize artifacts that may corrupt measurement results.

\section{Conclusion}

In conclusion, the present study revealed excellent measurement repeatability of the $A D C(0,800)$ and the estimated diffusion coefficient D', as well as good repeatability of the estimated perfusion fraction $f^{\prime}$ calculated from only three b-values using the simplified IVIM approach. In contrast to non-linear bi-exponential fittingbased approaches, the simplified approach yielded satisfactory results not only in liver tissue but also in malignant liver lesions in which fitting is difficult. Thus, the simplified approach may be helpful in the diagnosis and therapy monitoring of liver malignancies.

\section{Conflict of Interest}

Dr. Kukuk: Speakers bureau Bayer Healthcare and Philips Healthcare. The other authors declare that they have no conflict of interest.

\section{Widmung}

Diese Arbeit ist Herrn Univ.-Prof. Dr. med. Hans Heinz Schild gewidmet, bei dem wir uns herzlich für die langjährige und stete Unterstützung in allen klinischen und wissenschaftlichen Belangen bedanken möchten.

\section{References}

[1] Thoeny HC, Ross BD. Predicting and monitoring cancer treatment response with diffusion-weighted MRI. J Magn Reson Imaging 2010; 32: $2-16$

[2] Chiaradia M, Baranes L, Van Nhieu JT et al. Intravoxel incoherent motion (IVIM) MR imaging of colorectal liver metastases: are we only looking at tumor necrosis? J Magn Reson Imaging 2014; 39: 317-325

[3] Padhani AR, Koh DM. Diffusion MR imaging for monitoring of treatment response. Magn Reson Imaging Clin N Am 2011; 19: 181 - 209

[4] Padhani AR, Liu G, Koh DM et al. Diffusion-weighted magnetic resonance imaging as a cancer biomarker: consensus and recommendations. Neoplasia 2009; 11: 102-125

[5] Koh DM, Collins DJ. Diffusion-weighted MRI in the body: applications and challenges in oncology. Am J Roentgenol 2007; 188: 1622-1635

[6] Le Bihan D, Breton E, Lallemand D et al. Separation of diffusion and perfusion in intravoxel incoherent motion MR imaging. Radiology 1988; 168: $497-505$

[7] Koh DM. Science to practice: can intravoxel incoherent motion diffusionweighted MR imaging be used to assess tumor response to antivascular drugs? Radiology 2014; 272: 307-308

[8] Koh DM, Collins DJ, Orton MR. Intravoxel incoherent motion in body diffusion-weighted MRI: reality and challenges. Am J Roentgenol 2011; 196: $1351-1361$

[9] Cohen AD, Schieke MC, Hohenwalter MD et al. The effect of low b-values on the intravoxel incoherent motion derived pseudodiffusion parameter in liver. Magn Reson Med 2015; 73: 306-311

[10] Parente DB, Paiva FF, Oliveira Neto JA et al. Intravoxel Incoherent Motion Diffusion Weighted MR Imaging at 3.0 T: Assessment of Steatohepatitis and Fibrosis Compared with Liver Biopsy in Type 2 Diabetic Patients. PLOS ONE 2015; 10: 1-13 
[11] Lu PX, Huang H, Yuan J et al. Decreases in Molecular Diffusion, Perfusion Fraction and Perfusion-Related Diffusion in Fibrotic Livers: A Prospective Clinical Intravoxel Incoherent Motion MR Imaging Study. PLOS ONE 2014; 9: 1-12

[12] Guiu B, Petit JM, Capitan V et al. Intravoxel incoherent motion diffusionweighted imaging in nonalcoholic fatty liver disease: a 3.0-T MR study. Radiology 2012; 265: 96-103

[13] Luciani A, Vignaud A, Cavet M et al. Liver cirrhosis: intravoxel incoherent motion MR imaging-pilot study. Radiology 2008; 249: 891 - 899

[14] Kakite S, Dyvorne H, Besa C et al. Hepatocellular carcinoma: short-term reproducibility of apparent diffusion coefficient and intravoxel incoherent motion parameters at 3.0T. J Magn Reson Imaging 2015; 41: 149156

[15] Yoon JH, Lee JM, Yu MH et al. Evaluation of hepatic focal lesions using diffusion-weighted MR imaging: comparison of apparent diffusion coefficient and intravoxel incoherent motion-derived parameters. J Magn Reson Imaging 2014; 39: 276-285

[16] Andreou A, Koh DM, Collins DJ et al. Measurement reproducibility of perfusion fraction and pseudodiffusion coefficient derived by intravoxel incoherent motion diffusion-weighted MR imaging in normal liver and metastases. Eur Radiol 2013; 23: 428-434

[17] Wagner M, Doblas S, Daire JL et al. Diffusion-weighted MR imaging for the regional characterization of liver tumors. Radiology 2012; 264: $464-472$

[18] Li YT, Cercueil JP, Yuan J et al. Liver intravoxel incoherent motion (IVIM) magnetic resonance imaging: a comprehensive review of published data on normal values and applications for fibrosis and tumor evaluation. Quant Imaging Med Surg 2017; 7: 59-78

[19] Woo S, Lee JM, Yoon JH et al. Intravoxel incoherent motion diffusionweighted MR imaging of hepatocellular carcinoma: correlation with enhancement degree and histologic grade. Radiology 2014; 270: 758 767

[20] Lee JT, Liau J, Murphy P et al. Cross-sectional investigation of correlation between hepatic steatosis and IVIM perfusion on MR imaging. Magn Reson Imaging 2012; 30: 572-578

[21] Cho GY, Kim S, Jensen JH et al. A versatile flow phantom for intravoxel incoherent motion MRI. Magn Reson Med 2012; 67: 1710-1720

[22] Pieper C, Meyer C, Sprinkart AM et al. The value of intravoxel incoherent motion model-based diffusion-weighted imaging for outcome prediction in resin-based radioembolization of breast cancer liver metastases. Onco Targets and Therapy 2016; 9: 4089-4098

[23] Pieper CC, Willinek WA, Meyer C et al. Intravoxel Incoherent Motion Diffusion-Weighted MR Imaging for Prediction of Early Arterial Blood Flow Stasis in Radioembolization of Breast Cancer Liver Metastases. Journal of Vascular and Interventional Radiology 2016; 27: 1320-1328

[24] Pieper CC, Sprinkart AM, Meyer C et al. Evaluation of a Simplified Intravoxel Incoherent Motion (IVIM) Analysis of Diffusion-Weighted Imaging for Prediction of Tumor Size Changes and Imaging Response in Breast Cancer Liver Metastases Undergoing Radioembolization: A Retrospective Single Center Analysis. Medicine 2016; 95: 1 -9

[25] Penner AH, Sprinkart AM, Kukuk GM et al. Intravoxel incoherent motion model-based liver lesion characterisation from three b-value diffusionweighted MRI. Eur Radiol 2013; 23: 2773-2783
[26] Lewin M, Fartoux L, Vignaud A et al. The diffusion-weighted imaging perfusion fraction $f$ is a potential marker of sorafenib treatment in advanced hepatocellular carcinoma: a pilot study. Eur Radiol 2011; 21: $281-290$

[27] McBride GB. A proposal for strength-of-agreement criteria for Lin's Concordance Correlation Coefficient. NIWA Client Report 2005; HAM2005-062: 1 - 10

[28] Gurney-Champion OJ, Froeling M, Klaassen R et al. Minimizing the Acquisition Time for Intravoxel Incoherent Motion Magnetic Resonance Imaging Acquisitions in the Liver and Pancreas. Invest Radiol 2016; 51: $211-220$

[29] Lee Y, Lee SS, Kim N et al. Intravoxel incoherent motion diffusionweighted MR imaging of the liver: effect of triggering methods on regional variability and measurement repeatability of quantitative parameters. Radiology 2015; 274: 405-415

[30] Dyvorne H, Jajamovich G, Kakite $\mathrm{S}$ et al. Intravoxel incoherent motion diffusion imaging of the liver: optimal b-value subsampling and impact on parameter precision and reproducibility. Eur J Radiol 2014; 83: $2109-2113$

[31] Wang M, Li X, Zou J et al. Evaluation of Hepatic Tumors Using Intravoxel Incoherent Motion Diffusion-Weighted MRI. Medical Science Monitor 2016; 22: $702-709$

[32] Doblas S, Wagner M, Leitao HS et al. Determination of Malignancy and Characterization of Hepatic Tumor Type With Diffusion-Weighted Magnetic Resonance Imaging: Comparison of Apparent Diffusion Coefficient and Intravoxel Incoherent Motion-Derived Measurements. Investigative radiology 2013; 48: $722-728$

[33] Ichikawa S, Motosugi U, Ichikawa T et al. Intravoxel incoherent motion imaging of focal hepatic lesions. J Magn Reson Imaging 2013; 37: 1371 1376

[34] Mürtz P, Sprinkart AM, Reick M et al. Accurate IVIM model-based liver lesion characterisation can be achieved with only three b-value DWI. Eur Radiol 2018. doi:10.1007/s00330-018-5401-7

[35] Regini F, Colagrande S, Mazzoni LN et al. Assessment of Liver Perfusion by IntraVoxel Incoherent Motion (IVIM) Magnetic Resonance-DiffusionWeighted Imaging: Correlation With Phase-Contrast Portal Venous Flow Measurements. J Comput Assist Tomogr 2015; 39: 365-372

[36] Jajamovich GH, Dyvorne H, Donnerhack C et al. Quantitative liver MRI combining phase contrast imaging, elastography, and DWI: assessment of reproducibility and postprandial effect at 3.0 T. PLoS One 2014; 9: 1-8

[37] Dyvorne HA, Galea N, Nevers T et al. Diffusion-weighted Imaging of the Liver with Multiple b Values: Effect of Diffusion Gradient Polarity and Breathing Acquisition on Image Quality and Intravoxel Incoherent Motion Parameters-A Pilot Study. Radiology 2013; 266: 920-929

[38] Patel J, Sigmund EE, Rusinek $\mathrm{H}$ et al. Diagnosis of cirrhosis with intravoxel incoherent motion diffusion MRI and dynamic contrast-enhanced MRI alone and in combination: preliminary experience. J Magn Reson Imaging 2010; 31: 589-600

[39] Steudel A, Träber F, Reiser M. Hepatic tumors: relaxometry and quantitative tissue characterization with magnetic resonance imaging. Frontiers Eur Radiol 1993; 9: 45-61 